would be more lamentable or less hopeful than a consensus of opinion on the important problems that confront us in the domain of institutional reform. Such solidarity of thought, such unanimity in the verdict, would give us reason to pause and to ask ourselves whether it was the outcome of real, innate conviction, or merely the expression of impatience which leaps at the first suggestion and clings. with stubborn obstinacy to a ready-made decision which is supported by the influence of a majority.

We venture to think that no one interested in hospital reform and who has seriously reflected on the subject, will need any assistance in combating the preconceived notion that the voluntary hospital system is on its last legs. That being the case it is justifiable to ask what prevents us from co-operating in its defence and reorganisation. We have earnestly and conscientiously weighed; it is now the time to act. We assert that the time has come to attempt to draw certain definite conclusions from our extended considerations, to join together in attempting a solution of the difficulties that prevent, unanimous action, and to find a starting point. That, in fact, is the essential in co-opera. tion, and it is to co-operation that we must look for a settlement of the difficulties. Co-operation has meant much to the system of State insurance in the German Empire; it is no exaggeration to say that without it that system could never have attained the success which it undoubtedly has. It has meant equally much for the hospital system in Switzerland and Holland; it is likely to mean as much for the hospitals in our overseas dominions. When we have these examples before us, is it unreasonable or arrogant to demand that we should at least give co-operation amongst all agencies dealing with medical relief a fair trial in this country before we accept as proven the existence of a dilemma which implies an amount of social and institutional degeneration on which no country, however conceited, could afford to pride itself?

\title{
AUTHORSHIP AND AUTHORITY.
}

The pericdical criticism of the examination system as a test of merit has just come round again. In medicine, a good deal perhaps depends on examinations; because of the fact that nearly all distinguished medical men hold high qualifications, one seldom hears the question raised. Many hospital appointments, again, are confined to certain graduates and diplomates. To some extent medical journals are open to all. The resulting heap of literature is much too big, and shows far too much dross and very little ore, it is true, but no one can say truly that the only offenders are those who, if some had their way, would be constituted into a "lower branch." of the profession.

The list of original contributions to European or better-class American medical periodicals mostly consists, firstly, of a paper by some famous old emeritus or of a report of some set oration or lecture. Then come articles by well-known physicians or surgeons or sanitarians or pathologists, articles essential, fairly often, to students of the subject treated of, but which may be just thinly disguised puffs of the writer's professional ability, real or pretended: At the end are crowded in the efforts of youth or of those not high up the ladder of contemporary professional fame. These, to be candid, are mostly without value, but there is a residue of two or three a year which will live, albeit at first and for a considerable period in a state of suspended animation. For the sake of the last, as also on the principle of the " first bite," and to conciliate subscribers' opinion, it is customary to show a liberal attitude; and we think this course not only largeminded but also wholly wise. Coercive measures. would however be voted for by some who endorse: Oppenheimer's impatient written comment- " Weg. mit Dissertationen und Festschriften!"

Open opposition of that kind is rare in this: smoother-spoken country; but private opinion in certain quarters here is very similar. In a recent. conversation, the topic of which was a short article by an undistinguished writer raising a novel and. important point, it was said that he would do well to secure a higher qualification. Some objection orother was raised, whereupon the first speakernot, to be sure, an investigator himself, but usually the most diplomatic and conciliatory of men, exclaimed angrily - "Well, he mustn't expect much notice to be taken of what he says unless. he does!" Obscurantism like this, however, must surely be exceptional. None the less, philosophic note has to be taken of it, as of any other phenomenon. The ordinary " consultant" has doubtless. never very far from his mind the delights scorned, the fees paid, and the laborious days of his student life, as also a clear remembrance of the precariousness of his early career. As others-so far-have had the profit, he thinks that the honour should be his; and here indeed he might quote from the " Ethics " in confirmation. In a good many cases he is right, but the whole history of discovery shows that he may be wrong, and then the consequences of his mistake are overmuch to be atoned for by any number of previous just decisions. 